\title{
Nuclear Engineering Enrollments and Degrees Survey, 2009 Data
}

\section{SURVEY UNIVERSE}

The survey includes degrees granted between September 1, 2008, and August 31, 2009, and fall 2009 enrollments. Thirty-two academic programs reported having nuclear engineering programs during 2009, and data was provided by all thirty-two. The enrollment and degree data includes students majoring in nuclear engineering or in an option program equivalent to a major.

\section{DEGREE DATA}

Bachelor's Degrees. The number of B.S. degrees in 2009 by nuclear engineering programs decreased after five consecutive years of increases and was 13\% fewer than in 2008. (See Table 1.) The number of B.S. degrees in 2009 was still roughly double the numbers reported at the beginning of the decade and $50 \%$ greater than the number reported in 2005 . Nuclear engineering majors accounted for $95 \%$ of all B.S. degrees. (See Table 2.)

Graduate Degrees. The number of master's degrees in 2009 decreased after six consecutive years of increases, and was $10 \%$ fewer than in 2008 . The number of M.S. degrees in 2009 was still $75 \%$ greater than the numbers reported at the beginning of the decade and $35 \%$ greater than the number reported in 2005. The number of doctorate degrees decreased in 2009 to approximately the same number earned in 2007. (See Table 1.) The decrease in graduate degrees is unexpected as graduate enrollments have continuously increased since 2001 . Nuclear engineering majors accounted for $97 \%$ of the M.S. and $85 \%$ of the Ph.D. degrees. (See Table 2.)

Table 1. Nuclear Engineering Degrees, 2002 - 2009

\begin{tabular}{cccc} 
& \multicolumn{3}{c}{ Degrees } \\
\cline { 2 - 4 } Year & B.S. & M.S. & Ph.D. \\
\hline 2009 & 395 & 233 & 87 \\
2008 & 454 & 260 & 127 \\
2007 & 413 & 227 & 89 \\
2006 & 346 & 214 & 70 \\
2005 & 268 & 171 & 74 \\
2004 & 219 & 154 & 75 \\
2003 & 166 & 132 & 78 \\
2002 & $195^{\star}$ & 130 & 67
\end{tabular}

*Three programs were discontinued/out-of-scope after 2002 and not included in the 2003 survey. These three programs reported a total of 17 B.S. degrees in 2002.

Table 2. Nuclear Engineering Degrees, 2009, by Curriculum

\begin{tabular}{lrrc}
\multicolumn{1}{c}{ Curriculum } & B.S. & M.S. & Ph.D. \\
\hline Nuclear Engineering Major & 374 & 226 & 74 \\
Nuclear Engineering Option & 21 & 7 & 13
\end{tabular}




\section{ENROLLMENTS AND SHORT-TERM OUTLOOK FOR DEGREE TRENDS}

Undergraduate Students. In 2009, the reported enrollment of junior and senior nuclear engineering undergraduate students was over 1,500, an increase of about 15\% above the number reported in 2008. Undergraduate enrollments in 2009 were the largest reported since the mid 1980s. The growth in enrollments will likely generate an increase in the number of bachelor's degrees earned over the next couple of years. A larger increase is more likely to occur in two years (2011) as the undergraduate junior and senior enrollments in 2008 were basically the same as those in 2007.

Graduate Students. The reported enrollment of graduate student enrollment in 2009 was almost 1,300, about 5\% higher than in 2008, and roughly $30 \%$ higher than the enrollments reported in 2005 . In fact, graduate enrollments have increased annually since 2001 , but are still about $10 \%$ below the numbers reported from the mid 1970s through the early 1990s. The continued increase in graduate enrollment indicates that the number of both M.S. and Ph.D. degrees should increase for the next several years.

\section{CITIZENSHIP, GENDER, AND RACE/ETHNICITY OF DEGREE RECIPIENTS (TABLE 3.)}

Please note that citizenship, gender, and race/ethnicity data were not reported for 37 B.S. degree recipients. Percentages for the B.S. degrees are based on the 358 degrees for which data was reported.

Citizenship. Among B.S. degree recipients, $2.5 \%$ were non-U.S. citizens. Among M.S. degree recipients, $13 \%$ were non-U.S. citizens; and among Ph.D. degree recipients, almost 38\% were non-U.S. citizens. The higher percentages of non-U.S. citizens among graduate degree recipients is a continuation of a long-term trend common across graduate engineering academic programs.

Gender. Females comprised $18 \%$ of the B.S. degree recipients, $22 \%$ of the M.S. degree recipients, and $20 \%$ of the Ph.D. recipients.

Race/Ethnicity. Among the B.S. degree recipients, $13 \%$ of the U.S. citizens were members of minority groups. Among the M.S. degree recipients, $16 \%$ of the U.S. citizens were members of minority groups. Among the Ph.D. degree recipients, $20 \%$ of the U.S. citizens were members of minority groups.

Table 3. Citizenship, Gender, and Race/Ethnicity of Degree Recipients, ${ }^{1} 2009$

\begin{tabular}{lrrrrrr} 
& \multicolumn{2}{c}{ B.S. } & \multicolumn{2}{c}{ M.S. } & \multicolumn{2}{c}{ Ph.D. } \\
\cline { 2 - 7 } & Female & Male & Female & Male & Female & Male \\
\cline { 2 - 7 } Non-U.S. Citizens & 2 & 7 & 8 & 23 & 3 & 30 \\
U.S. Citizens & & & & & & \\
African/Black Americans & 2 & 11 & 2 & 2 & 0 & 0 \\
American Indians & 0 & 0 & 0 & 0 & 0 & 0 \\
Asian/Pacific Island Americans & 7 & 15 & 8 & 10 & 2 & 8 \\
Hispanic Americans & 4 & 8 & 2 & 8 & 0 & 1 \\
White/Caucasian Americans & 49 & 235 & 31 & 137 & 11 & 31 \\
Other or Unknown & 1 & 17 & 0 & 2 & 1 & 0 \\
Totals & 65 & 293 & 51 & 182 & 17 & 70
\end{tabular}

${ }^{1}$ Citizenship, gender, and race/ethnicity data was not available for 37 bachelor's degree recipients. 
Table 4. Nuclear Engineering Degrees, 2009, by Academic Institution (alphabetical by state and then university)

\begin{tabular}{|c|c|c|c|c|}
\hline \multirow[b]{2}{*}{ State } & \multirow[b]{2}{*}{ Name of Institution } & \multicolumn{3}{|c|}{$\begin{array}{c}\text { Degrees } \\
\text { Sept. 1, } 2008 \text { - Aug. 31, } 2009\end{array}$} \\
\hline & & B.S. & M.S. & Ph.D. \\
\hline $\mathrm{CA}$ & University of California, Berkeley & 11 & 9 & 5 \\
\hline $\mathrm{FL}$ & University of Florida & 23 & 19 & 12 \\
\hline GA & Georgia Institute of Technology & 32 & 24 & 1 \\
\hline ID & Idaho State University & 8 & 2 & 0 \\
\hline IL & University of Illinois at Urbana-Champaign & 17 & 2 & 4 \\
\hline IN & Purdue University & 20 & 11 & 6 \\
\hline KS & Kansas State University & 13 & 1 & 2 \\
\hline MA & Massachusetts Institute of Technology & 15 & 24 & 15 \\
\hline MA & University of Massachusetts, Lowell & 2 & 0 & 0 \\
\hline $\mathrm{MD}$ & University of Maryland & 0 & 4 & 0 \\
\hline $\mathrm{ME}$ & University of Maine & 0 & 0 & 0 \\
\hline MI & University of Michigan & 37 & 21 & 8 \\
\hline MO & Missouri University, Columbia & 0 & 3 & 2 \\
\hline MO & Missouri University of Science \& Technology & 25 & 6 & 0 \\
\hline NC & North Carolina State University & 24 & 12 & 6 \\
\hline NM & University of New Mexico & 6 & 9 & 2 \\
\hline NV & University of Nevada, Las Vegas & 0 & 2 & 1 \\
\hline NY & Rensselaer Polytechnic Institute & 30 & 3 & 0 \\
\hline NY & United States Military Academy & 10 & 0 & 0 \\
\hline $\mathrm{OH}$ & Air Force Institute of Technology & 0 & 7 & 0 \\
\hline $\mathrm{OH}$ & Ohio State University & 0 & 7 & 0 \\
\hline $\mathrm{OH}$ & University of Cincinnati & 5 & 7 & 0 \\
\hline OR & Oregon State University & 6 & 5 & 1 \\
\hline PA & Pennsylvania State University & 35 & 11 & 3 \\
\hline SC & South Carolina State University & 2 & 0 & 0 \\
\hline SC & University of South Carolina & 0 & 5 & 0 \\
\hline $\mathrm{TN}$ & University of Tennessee & 24 & 9 & 4 \\
\hline $\mathrm{TX}$ & Texas A\&M University & 32 & 13 & 8 \\
\hline $\mathrm{TX}$ & University of Texas & 4 & 2 & 0 \\
\hline UT & University of Utah & 0 & 3 & 0 \\
\hline VA & Virginia Commonwealth University ${ }^{1}$ & 0 & 0 & 0 \\
\hline WI & University of Wisconsin & 14 & 12 & 7 \\
\hline & TOTALS: & 395 & 233 & 87 \\
\hline
\end{tabular}


Prepared by: Analysis and Evaluation Group, Science Education Programs, Oak Ridge Institute for Science and Education, March 2010.

This document was prepared for U.S. Nuclear Regulatory Commission by the Oak Ridge Institute for Science and Education (ORISE) through an interagency agreement with the U.S. Department of Energy (DOE). ORISE is managed by Oak Ridge Associated Universities under DOE contract number DE-AC05-06OR23100.

The Oak Ridge Institute for Science and Education (ORISE) is a U.S. Department of Energy institute focusing on scientific initiatives to research health risks from occupational hazards, assess environmental cleanup, respond to radiation medical emergencies, support national security and emergency preparedness, and educate the next generation of scientists. ORISE is managed by Oak Ridge Associated Universities.

All opinions expressed in this report are the author's and do not necessarily reflect the policies and views of the U.S. Nuclear Regulatory Commission, the U.S. Department of Energy, or the Oak Ridge Institute for Science and Education or any of their employees. Nor does it necessarily reflect the policies and views of the sponsoring institutions of Oak Ridge Associated Universities. 